\title{
Hypothesis and conceptual framework Development of Cross Cultural Training and Perceived Success of Expatriates
}

\author{
Qamar Farooq ${ }^{1}$, Naveed Ahmad ${ }^{2}$, Muhammad Nouman Shafique ${ }^{3 *}$ \\ 1, 3 Scholar Preston University, Islamabad, Pakistan \\ 2Department of Business Administration, Lahore Leads University, Pakistan \\ `E-mail address: shafique.nouman@gmail.com, naveeddgk2010@gmail.com
}

\begin{abstract}
Rising trends of globalization in economic, managerial and social arenas have resulted in interpersonal contacts across the cultures. Multinational companies are increasingly focusing on trainings of their employees for improvement of performance. This research is based on the practical idea and literature review about the success of employees who are deputed for overseas assignments.

Various factors related to the success or failures of expatriates have been explored in this study and one of the important aspects "cross cultural training" has been focused to find its impact on success of expatriates. This study encompasses the definition of cross cultural training ranging to its importance and effects. Substantial investment pertaining to foreign subsidiaries fashions the management to expect for the high returns, on the other hand, failure of expatriates adds significantly in failure of companies in deed.

Proper cross cultural training of employees help them to shun the cultural shock and difficulties in adjustment abroad. For completion of this research, a very comprehensive questionnaire was designed basing on theoretical framework and a case study of expatriates of National Database and Registration Authority (NADRA) of Pakistan was carried out. Study found that there are multi-faceted uses of cross cultural training and it is one of the major sources to reduce cultural shock and premature return of the employees.

The research is not only useful for NADRA and Government Sector of Pakistan rather through conceptual work it is universally constructive for developing a general idea about cross cultural training and its impact on success of expatriates. This research specifically covered all related areas of expatriates of studied organization and findings have been discussed in order to grasp the relevant sides of topic by controlling rest of variables for getting potentially reliable results.
\end{abstract}

Keywords: NADRA; Expatriates; Training

\section{INTRODUCTION}

Wide growth in globalization has brought many players in new activities and tasks related to international business. Economic and business relations have become globally interconnected. This has carried many challenges out of which one is the active and apprised human resource and its management which is imperative for the success of international operations. Regardless of size and age of $\mathrm{MNC}$, problems have been commonly observed by 
corporations regarding expatriation of their employees. Failure in expatriate assignment is expensive for corporation, employee and even for family of employee. According to Swaak (1995), these failures can cause major hindrances in career of employee and damage to its family life.

Harrison (1994) found the reasons of cross-cultural management training programs which are found valuable for effective cross-cultural performance. Cross Cultural Training (CCT) can be defined as set of efforts made in formalized manner for preparing people for more effectual interpersonal relations and for success in job when they widely interact with the people from different cultures (Brislin \& Yoshida, 1994). As structured and sequenced program, organizations can impart Cross Cultural Training (CCT) that enables expatriate managers and their families to augment their talent and consciousness, gain massive knowledge, and build appropriate skills for functioning effectively in multi-cultures. A high strategic and financial cost is associated with high failure rate of individuals and organizations for not providing CCT to expatriates.

Success or failure of expatriates depends on the cultural knowledge of host-country (Nas, 2011). Effect of failure of expatriate is mostly taken by its premature return of person. Failures of expatriates on foreign assignments cause many problems for organization, employees and their families. In government sector, diplomats are placed abroad at the missions of their country and in private sector employees are posted for international operations, research and or for any other purpose relating to the company. National Database and Registration Authority is the biggest IT organization of Pakistan which is running its operations worldwide.

There are many studies in which researchers have found the need and impacts of CCT for different organizations and different countries. In scenario of Pakistan, yet this thing has to be evaluated for NADRA employees posted in NADRA missions abroad. For this purpose, operations of NADRA in abroad have to be known along with the proposed or alternate systems which can be used in abroad mission connecting front end with the back end. International Operations Department of NADRA is responsible for management of abroad operations with their major products of NICOP and POC offered in abroad. In order to complete this study in specified time, scope will be limited to POC systems and related activities and the necessary trainings needed.

Following research questions are to be answered in this study:

Q: 1 What is the impact of CCT in success or failure of expatriates?

Q: 2 What is the ratio of failure if CCT is not provided to the expatriates?

Q: 3 Does the impact of CCT on success or failure is same or different on both genders (male/female)?

In order to answer the above questions, study of present and alternate systems, current state of trainings provided to the expatriates under discussion, knowledge of the postings and placements and information about the structure of organization is necessary. Out of these many things, sufficient awareness is already available currently about present systems running in NADRA missions abroad. Know-how about the postings and placements is also present up to some extent.

This study is aimed to investigate and analyze cross-cultural training needs of expatriates and the current and proposed methods for Pre-departure and Post-Arrival training to expatriates and Diaspora. This research will ascertain the impact of CCT on success of NADRA employees posted abroad by achieving following objectives:

1. To find the ratio of failure if CCT is not provided to NADRA expatriates 
2. To determine the difference (if any) of impact of CCT on success or failure males and female

3. To find the importance of CCT for NADRA employees posted abroad by finding the impact of CCT on success of expatriates.

\section{LITERATURE REVIEW}

According to many writers such as Anderson (1999) and D'Netto (1997), there are four key factors that contribute towards success of an international assignment that are selection, preparation, Management Support and repatriation.

The objective of cross-cultural training is to educate members of one culture how to interact with members of another culture effectively. CCT is also important to prompt people to a rapid adjustment to their new positions as concluded by Mendenhall and Oddou (1991).

Marek and Leon (1992) identified some objectives of CCT which are related to increase in ability, access and better services; the ability to participate in international organizations, the access to modern technologies, ability to utilize experience of other public services and interact with international NGO's, better services for minorities in our respective countries and for national and multinational business. They added that unluckily it is common that programs and trainers are not aware and sensitive towards culture, legislative system and political values and norms of respective countries. Cultural compatibility of such programs is always important except of some highly technical training. Programs which we accept are designed for explicit administration as deemed fit for our particular administration.

Research of Deresky (2003) shows that most Multinational Corporations do not properly estimate the importance of the function of human resource planning in perspective of selection and training of managers detailed for abroad assignments. Cross Cultural Training has taken very important contributory role for apprising the expatriates about the cultural differences and adopting oneself in new environment and culture.

In view of Adler \& Bartholomew (1992), CCT provides transnational manager with the skills of managing tradeoffs. These tradeoffs are between opposing interests and decision making in choosing when to respond locally and when to focus on global conglomeration. Rhinesmith (1993) supported their view and furnished the objectives of CCT to supply the skills to promote organizational learning. Through organizational learning, organization, ultimately can improve its capability in responding and adapting the uncertainties and global changes.

Bartlett \& Ghoshal (1992) conducted the research on CCT and found that CCT helps in coordinating the activities and it helps capabilities to link up across national and functional borders. They also deduced that CCT facilitates in recognizing risks and opportunities across these boundaries.

Rhinesmith (1993) delineated that CCT is aimed to provide skills to the managers for working with people of other cultures with no privileged areas for home nationality.

Dowling and Schuler (1990) concluded that skills which are gained by transnational managers are majorly related to building effective teams across business related, national and functional lines.

Adler \& Bartholomew (1992) also found that CCT results in good management of information sharing worldwide in collaboration with global partners. It is useful to give skills to transfer gained knowledge of worldwide operations. 


\section{METHODOLOGY}

This research will be based on study of NADRA employees posted abroad. This will also have the representation of employees of Immigration and Passport and Ministry of Foreign Affairs as these setups and sections work together in mission working abroad. Before the commencement of study, knowledge of present and alternate systems of NADRA, current state of trainings provided to the expatriates under discussion, knowledge of the postings and placements and information about the structure of organization is necessary. Out of these many things, sufficient awareness is already available currently about present systems running in NADRA missions abroad.

Know-how about the postings and placements is also present up to some extent. However, further information will be obtained through proper channel. According to available information, around 40 Pak Based and 65 Local based employees remain enrolled on average at missions in abroad. This size of population will be convenient in finding the each element of study; therefore total population will be studied in this research. The information will be verified from record of organization once the formal research survey is started.

Study will be carried out in National Database and Registration Authority (NADRA) HQ, Islamabad. NADRA is an autonomous body dealing with the registration of Pakistani and Pakistani Origin people along with several other projects. Headed by Chairman, NADRA is having Deputy Chairman and Chiefs running different directorates of NADRA.

Operations are seen Chief Operating Officer in Ops Division. There is 1x directorate and $4 \mathrm{x}$ departments working under Ops Division of NADRA. International Operations Department is the one of the department working under Ops division and looking after overseas operations of NADRA. The two main products with which IOD is dealing are NICOP and POC. NADRA posts its employees abroad to run the overseas operations. NADRA deals with the Pakistanis, overseas Pakistanis and Pakistani Origin people.

NADRA is also having other clients for its various projects of different departments of Government out of which few are ECP project, armed license project and others. Regarding international operations, main issue is the working of NADRA employees posted abroad. IOD has the central concerns about their training and success. After refining the research model and variables of success, the relationship of IV and DVs will be measured and performance of expatriates will be analyzed who get the CCT and will be compared with those who don't get. Effects of pre-departure and post-arrival trainings will be found.

\section{DISCUSSION AND CONCLUSION}

In present study, different forms of cross cultural training have been taken as its variables to find the impact on perceived success of expatriates. Success is the inverse of failure; that's why it became convenient to work on this research without quantifying this variable by taking the perception of respondent important factor for finding the impact of CCT. Critical analysis of definition of failure in respect of expatriate has been made by not limiting it to pre-mature return. Analysis tells language training has positive impact on perceived success of expatriates as pre-departure cultural training and post-arrival cultural orientation do.

The results of present study show that there are many benefits of CCT as the most respondents believe that $\mathrm{CCT}$ can be beneficial to the work adjustment of expatriates and it saves from cultural shock. Effective CCT very effectively guides the employees for their 
work in a diversified culture. Despite of numerous benefits of CCT it has been observed that MNCs do not usually provide CCT to their employees either due to mismanagement or due to feeling it unnecessary. Though, the current ratio of failure of NADRA employees posted abroad is not that much high but still it can be reduced by providing CCT.

Basing on data analysis and results of survey, it can be concluded that Cross Cultural Training is very important for the employees who are posted abroad, it has almost similar and significantly positive impact on perceived success of both genders.

Following are the practical implications of research:

a. CCT must be provided to all the employees going abroad for assignments of duration 6months or more.

b. Curriculum of Pre-Departure Cross Cultural Training, Post-Arrival CCT and of Language training may be arranged in consultation with the CCT experts.

Result of data analysis of survey reveals that employees need 5 days pre-departure CCT, 2 day Post-Arrival CCT and 1 month language training to the expatriates hence same should be provided to all prospective employees not with major time difference of their posting and the date of taking charge.

\section{Hypotheses for Future Studies}

H1: Cross Cultural Training is important for employees posted on foreign assignments

$\mathrm{H} 2$ : Cross Cultural Training has positive impact on success of expatriates

H3: Impact of Cross Cultural Training is same on both genders

\section{Theoretical Framework for Future Studies}

After literature review about CCT, it has been found that skill development; expatriate's adjustment and performance are the main dependent variables in context of CCT (Black and Mendenhall, 1990). On the other hand, cultural orientation, environmental briefing and language training are three among six main types of CCT Tung (1987), Lee \& Sukocu, (2007), hence can be taken as measures for CCT.

Through research of Nas (2011), it has been revealed that cultural shock and pre-mature returns can be minimized by imparting CCT which are the characteristics adversely affecting the success of expatriates or which cause failure of expatriates in other words. Researchers have extensively discussed about pre-departure and post-arrival training but according to my opinion both trainings should relate to cultural orientation more. So I am going to take the following IVs and DVs variables in my research:

\section{IVs:}

1. Language training

2. Pre-departure Cultural Training

3. Post-arrival Cultural Orientation

DV:

Perceived Success of Expatriates 
Study will be carried out basing on following model:

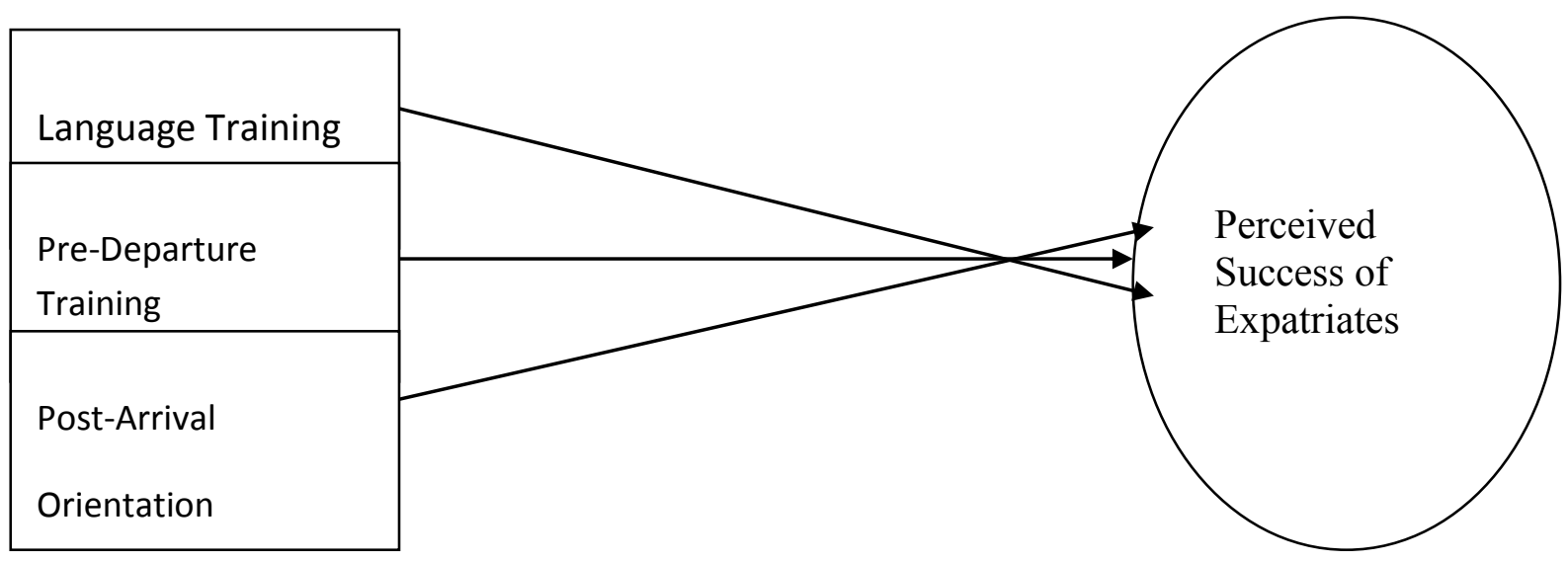

\section{CONCLUSION}

Various factors related to the success or failures of expatriates have been explored in this study and one of the important aspects "cross cultural training" has been focused to find its impact on success of expatriates. This study encompasses the definition of cross cultural training ranging to its importance and effects. Substantial investment pertaining to foreign subsidiaries fashions the management to expect for the high returns, on the other hand, failure of expatriates adds significantly in failure of companies in deed.

Proper cross cultural training of employees help them to shun the cultural shock and difficulties in adjustment abroad. For completion of this research, a very comprehensive questionnaire was designed basing on theoretical framework and a case study of expatriates of National Database and Registration Authority (NADRA) of Pakistan was carried out. Study found that there are multi-faceted uses of cross cultural training and it is one of the major sources to reduce cultural shock and pre-mature return of the employees.

\section{References}

[1] Albert, R. D. (1986). "Conceptual framework for the development and evaluation of cross-cultural orientation programs." International Journal of Intercultural Relations, 10, 197-213.

[2] Adler, N.J. \& Bartholomew, S. (1992). "Managing globally competent people." Academy of Management Executive, 6(3), 52-65.

[3] Bartlett, C. A. \& Ghoshal, S. (1989). Managing Across Borders. Boston, MA: Harvard Business School Press.

[4] Black, J. S. \& Mendenhall, M. (1990). Cross-cultural training effectiveness: A review and a theoretical framework for future research. The Academy of Management Review, Vol. 15, No. 1, pp. 113-136.

[5] Brislin, R.W. (1979), "Orientation programs for cross-cultural preparation”, in Marsella, A.J., 
[6] Tharp, G. and Ciborowski, T.J. (Eds), Perspectives on Cross-cultural Psychology, Academic Press, Orlando, FL, pp. 87-304.

[7] Brislin, R.W. and Petersen, P. (1986), Cross-Cultural Orientation Programs, The Gartner Press, New York, NY.

[8] Brislin, R. W., \& Yoshida, T. (Eds.) (1994). Improving intercultural interactions: Models for cross-cultural training programs. Thousand Oaks, CA: Sage Publications.

[9] Dowling, P. J. \& Schuler, R. S. (1990). International Dimensions of Human Resource Management. Boston, MA: PWS-Kent Publishing.

[10] Harrison, J. K. (1992). "The individual and combined effects of behavior modeling and the cultural assimilator in cross-cultural management training." Journal of Applied Psychology, 77 (6), 952-962.

[11] Harrison, J. Kline (1994): Developing successful expatriate managers: a framework for the structural design and strategic.Human Resource Planning.

[12] Lee, L., \& Sukoco, B. M. (2007). The effects of expatriate personality and cultural intelligence on the expatriate adjustment: The moderating role of expatriate. Proceeding of the $13^{\text {th }}$ Asia Pasific Management Conference, Melbourne, Australia, pp. 922-931.

[13] Mendenhall, M. and Oddou, G. (1991), "Toward a comprehensive model of international adjustment: an integration of multiple theoretical perspectives", Academy of Management Review, Vol. 16 No. 2, pp. 291-317.

[14] Marek, D. M. and Kozminski, L. (1992) Academy of Entrepreneurship and Management in Warsaw (Poland) and University of Manitoba (Canada)

[15] Mendenhall, M.E. and Stahl, G. (2000), "Expatriate training and development: where do we go from here?", Human Resource Management, Vol. 39 No. 2/3, pp. 251-65.

[16] M.K.Anderson, J. R. (1985). Cognitive Psychology and its Implications. New York, NY: W. H. Freeman and Company.

[17] Rhinesmith, S. H. (1993). A Manager's Guide to Globalization. Homewood, IL: Business One Irwin. Six keys to success in a changing world.

[18] Schuler, R. S., Dowling, P. J., \& De Cieri, H. (1993). "An integrative framework of strategic international human resource management." Journal of Management, 19(2), 419-459.

[19] Tung, R. L. (1987). Expatriate assignments: enhancing success and minimizing failure. The Academy of Management Exacutive, Vol. 1. No. 2, pp. 117-125.

[20] Nas, Z. (2011). The Effect Of Cross Cultural Training On The Performance Of Expatriates In Business Organizations. Diss. National University of Modern Languages, Islamabad, 2011. 